\title{
Efficacy and safety of intensity-modulated radiotherapy alone versus intensity- modulated radiotherapy plus chemotherapy for treatment of intermediate-risk nasopharyngeal carcinoma
}

Omer Aftab ${ }^{1,2 \dagger}$, Shufang Liao ${ }^{1 \dagger}$, Rongjun Zhang ${ }^{1+}$, Nan Tang $^{3+}$, Meiqing Luo ${ }^{4}$, Bin Zhang ${ }^{5}$, Sanjeev Shahi ${ }^{2}$, Raju Rai ${ }^{2}$, Jazib Ali ${ }^{2}$ and Wei Jiang ${ }^{1,6^{*}}$

\begin{abstract}
Background: This study directs to evaluate the efficacy and safety of intensity-modulated radiotherapy (IMRT) alone versus IMRT plus chemotherapy in intermediate-risk NPC (stage II and $\mathrm{T}_{3} \mathrm{~N}_{0} \mathrm{M}_{0}$ ).

Methods: A total of 124 patients with stage II and $T_{3} N_{0} M_{0} N P C$ were pair-matched (1:1 ratio) to form two groups: an IMRT-alone group and an IMRT/chemotherapy group. Survival outcomes (overall survival [OS], disease-free survival [DFS], locoregional relapse-free survival [LRRFS], distant metastasis-free survival [DMFS]) and treatmentrelated grade 3-4 acute toxicity events were compared between the groups.

Results: Survival outcomes for patients with stage II and $\mathrm{T}_{3} \mathrm{~N}_{0} \mathrm{M}_{0} \mathrm{NPC}$ were quiet comparable between patients treated with IMRT alone versus patients treated with IMRT/chemotherapy: 5 -year OS was $91.9 \%$ vs. 90.3\%, respectively ( $P=0.727)$; DFS was $87.1 \%$ vs. $88.7 \%$, respectively ( $P=0.821)$; LRFFS was $96.8 \%$ vs. $95.2 \%$, respectively $(P=0.646)$, and DMFS was $91.9 \%$ vs. $91.5 \%$, respectively $(P=0.955)$. Grade 3 acute toxicities were significantly higher with IMRT/ chemotherapy than with IMRT alone: mucositis, $15 \%$ vs. $5 \%(P=0.004)$; leukopenia/neutropenia, $8 \%$ vs. $1 \%(P<0.015)$; and nausea/vomiting, $22 \%$ vs. $3 \%(P<0.001)$.

Conclusion: For intermediate-risk (stage II and $\mathrm{T}_{3} \mathrm{~N}_{0} \mathrm{M}_{0}$ ) NPC patients, the addition of chemotherapy to IMRT does not appear to provide any survival benefit. Moreover, grade 3 acute toxicities are also more common in patients receiving IMRT plus chemotherapy.
\end{abstract}

Keywords: Intermediate risk, Intensity-modulated radiation therapy, Chemoradiotherapy, Nasopharyngeal carcinoma

\footnotetext{
* Correspondence: weijiang@glmc.edu.cn

${ }^{+}$Omer Aftab, Shufang Liao, Rongjun Zhang and Nan Tang contributed equally to this work.

'Department of Radiation Oncology, Affiliated Hospital of Guilin Medical University, 15 Lequn Road, Guilin 541001, People's Republic of China

${ }^{6}$ Department of Oncology, People's Hospital of Gongcheng Yao Autonomous County, Guilin 542500, China

Full list of author information is available at the end of the article
}

(c) The Author(s). 2020 Open Access This article is licensed under a Creative Commons Attribution 4.0 International License, which permits use, sharing, adaptation, distribution and reproduction in any medium or format, as long as you give appropriate credit to the original author(s) and the source, provide a link to the Creative Commons licence, and indicate if changes were made. The images or other third party material in this article are included in the article's Creative Commons licence, unless indicated otherwise in a credit line to the material. If material is not included in the article's Creative Commons licence and your intended use is not permitted by statutory regulation or exceeds the permitted use, you will need to obtain permission directly from the copyright holder. To view a copy of this licence, visit http://creativecommons.org/licenses/by/4.0/ The Creative Commons Public Domain Dedication waiver (http://creativecommons.org/publicdomain/zero/1.0/) applies to the data made available in this article, unless otherwise stated in a credit line to the data. 


\section{Background}

Nasopharyngeal carcinoma (NPC) is common in the southern regions of China, particularly in Guangdong and Guangxi provinces $[1,2]$. Because of the biological characteristics of NPC, radiotherapy is the primary treatment modality.

Earlier, in the era of two-dimensional radiotherapy (2D-RT), chemoradiotherapy was the standard treatment for intermediate-risk NPC (stage II and T3NOM0). Concurrent chemoradiotherapy (CCRT) was shown to provide a considerable survival benefit for patients with stage II NPC [3, 4]. At present, "three-dimensional conformal radiotherapy (3DCRT) and the more advanced intensity-modulated radiotherapy (IMRT) have largely replaced 2D-RT, which enable the delivery of a higher and more accurate dose to a tumor target while sparing organs at risk [5], but CCRT is still considered the most suitable treatment for locoregionally advanced NPC [6]. However, some researchers reported that patients treated with CCRT have similar survival outcomes as those treated with only IMRT [7]. Moreover, stratified analysis demonstrated that, the addition of chemotherapy to IMRT did not significantly improve survival in stage II NPC subgroups. For example, Chen et al. and Sun et al. reported that the stage T3NOMO subgroup have similar survival to stage II $[5,8]$. Whether CCRT is superior to the IMRT alone for intermediate-risk NPC needs to be clarified. Hence, we included stage II and T3N0M0 disease as intermediate-risk NPC in our study, which would help in establishing individualized IMRT treatment protocols for stage II and T3N0M0 NPC.

The focus of the present study was to compare the efficacy and safety of IMRT alone versus IMRT plus chemotherapy in intermediate-risk (stage II and T3NOM0) NPC patients.

\section{Materials and methods Patients}

The patients for this retrospective study were selected from among those hospitalized between 2011 and 2014 in the Department of Radiation Oncology at the affiliated hospital of Guilin Medical University, Nanxishan Hospital of Guangxi Zhuang Autonomous Region and the Wuzhou Red Cross Hospital. Patients were eligible for inclusion in this study if they had 1) newly diagnosed, intermediate-risk (stage II and T3NOM0) NPC; 2) Eastern Cooperative Oncology Group performance status $\leq 1$; and 3) completed radical IMRT with or without chemotherapy (i.e., induction chemotherapy, neoadjuvant chemotherapy, and/or CCRT). Patients were excluded if they had 1) history of previous anticancer treatment or 2) history of another malignant tumor.

Patients were pair-matched [9] to maximize comparability between groups. Matching was performed for the following factors, with a descending hierarchy of priority: treatment regimen (IMRT vs. IMRT-chemotherapy); $\mathrm{T}$ category (T1 vs. T2 vs. T3); $\mathrm{N}$ category (N0 vs. N1); TNM stage (II vs. III [T3NOMO]); sex (male vs. female); age ( $\leq 45$ years vs. $>45$ years); and WHO histology (type II vs. type III). When multiple matched-pair combinations were possible, the pair with the closest admission dates was selected. All pairs were matched for at least five of the seven factors. Thus, we had two matched groups: one group comprising patients treated with IMRT alone (the IMRT-alone group) and another group comprising patients treated with IMRT plus chemotherapy (the IMRT/chemotherapy group). Survival outcomes and treatment-related toxicities were compared between the groups.

This study was approved by the Medical Ethics Committee of Affiliated Hospital of Guilin Medical University, Nanxishan Hospital of Guangxi Zhuang Autonomous Region and Wuzhou Red Cross Hospital. The need for informed consent was waived in view of the retrospective nature of the study.

\section{Pretreatment workup}

Initial workup included clinical and laboratory examinations (hematologic and biochemistry profiles); fiberoptic endoscopy of nasopharynx; magnetic resonance imaging (MRI) or contrast-enhanced computed tomography (CECT) of the head and neck to evaluate the extent of the primary tumor and regional lymph nodes involvement; and bone scintigraphy, chest radiography or CECT, and ultrasonography of the abdominal region to exclude distant metastasis. All patients were restaged according to the 7th edition of the Union International Centre le Cancer /American Joint Committee on Cancer (UICC/AJCC) system [10].

\section{Radiotherapy}

All patients received radical IMRT with 6-MV X-rays. The gross tumor volume (GTVnx) included the primary tumor as defined on MRI. Metastatic cervical lymph nodes were defined as GTVnd. The high-risk region was defined as clinical target volume 1 (CTV1) and included the whole nasopharyngeal cavity plus the GTVnx, with a margin of $5-10 \mathrm{~mm}$. The low-risk area was defined as CTV2 and encompassed CTV1 with a margin of 3-5 mm, clivus, parapharyngeal space, skull base, sphenoid sinus, pterygoid fossae and the lower neck, cervical lymph nodes and the supraclavicular lymphatic drainage region have been included in CTV2 according to the NCCN guideline. The total prescribed dose was 6670 Gy/31-33 fractions to the planning target volume (PTV) of GTVnx and 66-70 Gy/32-33 fractions to the PTV of GTVnd; a dose of $56-60 \mathrm{~Gy} / 30$ fractions to the PTV of CTV1 and $50 \mathrm{~Gy} / 30$ fractions to the PTV of 
Table 1 Baseline characteristics of patients in the two groups

\begin{tabular}{|c|c|c|c|}
\hline Characteristic & IMRT group $(n=62)$ & IMRT/chemotherapy group $(n=62)$ & $P$ \\
\hline Age & & & 0.055 \\
\hline$\leq 45$ years & $15(24.2 \%)$ & $25(40.3 \%)$ & \\
\hline$>45$ years & $47(75.8 \%)$ & $37(59.7 \%)$ & \\
\hline Sex & & & 1.000 \\
\hline Male & $44(71.0 \%)$ & $44(71.0 \%)$ & \\
\hline Female & $18(29.0 \%)$ & $18(29.0 \%)$ & \\
\hline Histology & & & 0.144 \\
\hline WHO type II & $2(3.2 \%)$ & $6(9.7 \%)$ & \\
\hline WHO type III & $60(96.8 \%)$ & $56(90.3 \%)$ & \\
\hline T category & & & 0.431 \\
\hline $\mathrm{T} 1$ & $14(22.6 \%)$ & $18(29.0 \%)$ & \\
\hline $\mathrm{T} 2$ & $41(66.1 \%)$ & $34(54.8 \%)$ & \\
\hline $\mathrm{T} 3$ & $7(11.3 \%)$ & $10(16.1 \%)$ & \\
\hline $\mathrm{N}$ category & & & 0.701 \\
\hline No & $21(33.9 \%)$ & $19(30.6 \%)$ & \\
\hline N1 & $41(66.1 \%)$ & $43(69.4 \%)$ & \\
\hline TNM stage & & & 0.433 \\
\hline$\|$ & $55(88.7 \%)$ & $52(83.9 \%)$ & \\
\hline III (T3NOMO) & 7 (11.3\%) & 10 (16.1\%) & \\
\hline
\end{tabular}

All data are $\mathrm{n}(\%)$

IMRT Intensity-modulated radiotherapy, WHO World Health Organization

CTV2 were delivered with first 30 fractions. All patients received one fraction per day, 5 days per week.

\section{Chemotherapy}

Patients in the IMRT/chemotherapy group received three cycles of chemotherapy (cisplatium, $80 \mathrm{mg} / \mathrm{m}^{2}$ ) concurrently with radiotherapy, with intervals of 21 days between cycles.

\section{Follow-up}

Follow-up duration was calculated from the first day of therapy to the date of last examination or death. At each follow-up visit, patients underwent physical examination, nasopharyngoscopy, ultrasonography of the abdomen, and chest radiography. CT scan or MRI of the head and neck region was conducted every 3 months during the first 2 years, and then every 6-12 months until the end of the

Table 2 Five-year survival outcomes of patients treated with IMRT alone and IMRT plus chemotherapy

\begin{tabular}{llll}
\hline Variable & IMRT group $(n=62)$ & IMRT/chemotherapy group $(n=62)$ & $H R(95 \% \mathrm{Cl})$ \\
\hline OS (\%) & & & $1.235(0.377-4.048)$ \\
At 3 years & $93.5 \%$ & $91.9 \%$ & 0.727 \\
At 5 years & $91.9 \%$ & $90.3 \%$ & $0.890(0.323-2.453)$ \\
DFS (\%) & & & \\
At 3 years & $88.7 \%$ & $90.3 \%$ & 0.821 \\
At 5 years & $87.1 \%$ & $88.7 \%$ & $1.515(0.253-9.066)$ \\
LRRFS (\%) & & & 0.646 \\
At 3 years & $96.8 \%$ & $95.2 \%$ & $1.037(0.300-3.581)$ \\
At 5 years & $96.8 \%$ & $95.2 \%$ & \\
DMFS (\%) & & & 0.955 \\
At 3 years & $93.5 \%$ & $95.2 \%$ & \\
At 5 years & $91.9 \%$ & $91.5 \%$ & \\
\hline
\end{tabular}

IMRT Intensity-modulated radiotherapy, HR Hazard ratio, CI Confidence interval, OS Overall survival, DFS Disease-free survival, LRRFS Locoregional relapse-free survival, DMFS Distant Metastasis-free survival 
study or death. For patients with suspected locoregional recurrence or distant metastasis, additional examinations were performed at the discretion of the treating physician. The primary endpoint was overall survival (OS), and the secondary endpoints were disease-free survival (DFS), locoregional relapse-free survival (LRRFS), distant metastasis-free survival (DMFS), and treatment-related toxicity. OS was defined as the time from registration to death from any cause or last follow-up; DFS was defined as the time from registration to treatment failure or death from any case; LRRFS was defined as the time from registration to first local or regional relapse or last follow-up; and DMFS was defined as the time from registration to first detection of distant metastasis or death from any cause. The Radiation Therapy Oncology Group (RTOG) radiation morbidity scoring criteria [6] and Common Terminology Criteria for Adverse Events (version 3.0) were used to grade the late toxicities of radiotherapy.

\section{Statistical analysis}

The chi-square test and Fisher exact test were used to compare patient characteristics between the IMRT-alone group and the IMRT/chemotherapy group. KaplanMeier method and the log-rank test were used to analyze OS, DFS, LRRFS, and DMFS. Multivariate Cox proportional hazards model with backward elimination was used to identify the independent predictors of different outcomes; the hazard ratios (HRs), with 95\% confidence intervals (CIs), were calculated. SPSS 19.0 (IBM Corp., Armonk, NY, USA) was used for statistical analysis. All statistical tests were two-sided, and $P \leq 0.05$ was considered statistically significant.

\section{Results}

\section{Patient characteristics}

Out of 215 patients assessed, 124 met the study eligibility criteria. These 124 patients included 88 men and 36 women (male-female ratio, 2.4:1), with a median age of 45 years (range $18-70$ years). The 124 patients were separated into two pair-matched groups: the IMRT-alone group $(n=62)$ and the IMRT/chemotherapy group $(n=62)$. The two groups were approximate with respect to baseline characteristics (Table 1).

All patients were restaged according to the 7th edition AJCC/UICC staging system; 22 patients were reclassified as T1, 75 were reclassified as T2, and 17 as T3. In addition, 40 patients were reclassified as $\mathrm{NO}$, and 84 were reclassified as $\mathrm{N} 1$.
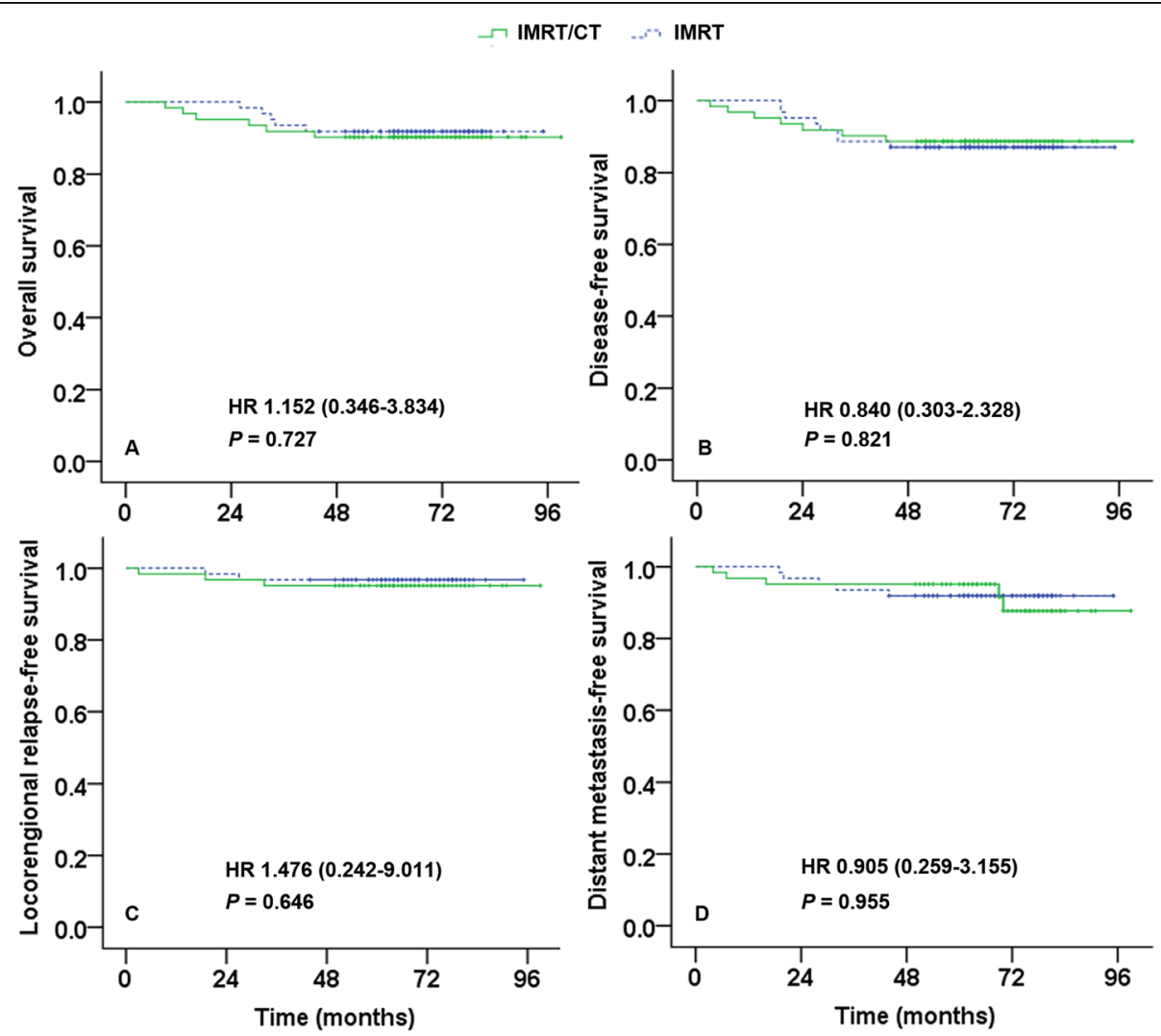

Fig. 1 Kaplan-Meier curves for overall survival (a), disease-free survival (b), locoregional recurrence-free survival (c), and distant metastases-free survival (d) in stage II and T3NOMO NPC patients treated with IMRT/chemotherapy and IMRT alone 
Table 3 Results of multivariate analysis showing the significant prognostic factors for different survival outcomes in nasopharyngeal carcinoma patients

\begin{tabular}{|c|c|c|c|}
\hline Factor & Hazard ratio & $95 \% \mathrm{Cl}$ & $P$ \\
\hline \multicolumn{4}{|l|}{ Overall survival } \\
\hline Chemotherapy (IMRT vs. IMRT/CT) & 1.152 & $0.346-3.834$ & 0.818 \\
\hline Age ( $\leq 45$ years vs. $>45$ years) & 1.307 & $0.347-4.930$ & 0.692 \\
\hline Sex (male vs. female) & 0.909 & $0.239-3.465$ & 0.889 \\
\hline TNM stage (II vs. III [T3NOMO]) & 5.797 & $1.768-19.007$ & 0.004 \\
\hline \multicolumn{4}{|l|}{ Disease-free survival } \\
\hline Chemotherapy (IMRT vs. IMRT/CT) & 0.840 & $0.303-2.328$ & 0.738 \\
\hline Age ( $\leq 45$ years vs. $>45$ years) & 1.049 & $0.351-3.135$ & 0.932 \\
\hline Sex (male vs. female) & 0.590 & $0.166-2.092$ & 0.414 \\
\hline TNM stage (II vs. III [T3NOMO]) & 4.990 & $1.772-14.047$ & 0.002 \\
\hline \multicolumn{4}{|l|}{ Locoregional relapse-free survival } \\
\hline Chemotherapy (IMRT vs. IMRT/CT) & 1.476 & $0.242-9.011$ & 0.673 \\
\hline Age ( $\leq 45$ years vs. $>45$ years) & 0.832 & $0.136-5.080$ & 0.842 \\
\hline Sex (male vs. female) & 1.015 & $0.212-3.457$ & 0.973 \\
\hline TNM stage (II vs. III [T3NOM0]) & 1.575 & $0.176-14.099$ & 0.685 \\
\hline \multicolumn{4}{|l|}{ Distant metastasis-free survival } \\
\hline Chemotherapy (IMRT vs. IMRT/CT) & 0.905 & $0.259-3.155$ & 0.875 \\
\hline Age ( $\leq 45$ years vs. $>45$ years) & 1.075 & $0.270-4.271$ & 0.919 \\
\hline Sex (male vs. female) & 0.950 & $0.241-3.736$ & 0.941 \\
\hline TNM stage (II vs. III [T3NOMO]) & 4.705 & $1.322-16.751$ & 0.017 \\
\hline
\end{tabular}

IMRT Intensity-modulated radiotherapy, Cl Confidence interval, CT Chemotherapy

\section{Survival outcomes}

Survival outcomes were approximate between the IMRT-alone group and the IMRT/chemotherapy group (Table 2): 5-year OS was $91.9 \%$ vs. $90.3 \%$, respectively $(P=0.727$; Fig. 1a); DFS was $87.1 \%$ vs. $88.7 \%$, respectively $(P=0.821$; Fig. 1b); LRFFS was $96.8 \%$ vs. $95.2 \%$, respectively $(P=0.646$; Fig. $1 \mathrm{c})$, and DMFS was $91.9 \%$ vs. $91.5 \%$, respectively $(P=0.955$; Fig. $1 d)$. Multivariate analysis (Table 3) showed that treatment (IMRT/chemotherapy vs. IMRT-alone) was not an independent prognostic factor for OS $(\mathrm{HR}=1.152 ; 95 \% \mathrm{CI}, 0.346-3.834 ; P=0.818)$, DFS $(\mathrm{HR}=0.840 ; 95 \% \mathrm{CI}, 0.303-2.328 ; \quad P=0.738), \quad$ LRFFS $(\mathrm{HR}=1.476 ; 95 \% \mathrm{CI}, 0.242-9.011 ; P=0.673)$, or DMFS $(\mathrm{HR}=0.905 ; 95 \% \mathrm{CI}, 0.259-3.155 ; P=0.875)$.

Treatment toxicities and compliance

All patients in both treatment arms completed the prescribed dose of IMRT. However, not all patients completed chemotherapy; the reasons for withdrawal of cisplatin included refusal by the patient, severe

Table 4 Treatment-related toxicities in the two groups

\begin{tabular}{|c|c|c|c|c|c|}
\hline \multirow[t]{2}{*}{ Toxicity } & \multicolumn{2}{|c|}{ IMRT $\operatorname{arm}(n=62)$} & \multicolumn{2}{|c|}{ IMRT/CT $\operatorname{arm}(n=62)$} & \multirow[t]{2}{*}{$P$} \\
\hline & Grade 3 & Grade 4 & Grade 3 & Grade 4 & \\
\hline Skin reaction (radiation-related) & 4 & 0 & 10 & 0 & 0.089 \\
\hline Mucositis (radiation-related) & 5 & 0 & 15 & 0 & 0.004 \\
\hline Vomiting /Nausea & 3 & 0 & 22 & 0 & $<0.001$ \\
\hline Leukopenia/neutropenia & 1 & 0 & 8 & 0 & 0.015 \\
\hline Thrombocytopenia & 0 & 0 & 2 & 0 & 0.496 \\
\hline Anemia & 0 & 0 & 2 & 0 & 0.496 \\
\hline Dry mouth & 2 & 0 & 2 & 0 & 1.000 \\
\hline Nephrotoxicity & 0 & 0 & 0 & 0 & - \\
\hline Hepatoxicity & 0 & 0 & 0 & 0 & - \\
\hline
\end{tabular}


mucositis, and prolonged severe neutropenia. The leading grade 3 acute toxic effects during treatment were hematologic and gastrointestinal reactions (Table 4). No grade 4 or 5 toxicity (death) occurred during treatment. The incidence of grade 3 acute toxic effects was significantly higher in the IMRT/chemotherapy group than in the IMRT-alone group: the incidence of grade 3 hematologic toxicity (leukopenia/neutropenia) was $8 \%$ vs. $1 \%$, respectively $(P<0.015)$; the incidence of grade 3 gastrointestinal toxicity (nausea/vomiting) was $22 \%$ vs. $3 \%$, respectively $(P<0.001)$; and the incidence of grade 3 mucositis was $15 \%$ vs. $5 \%$, respectively $(P=0.004)$. No patient had grade 4 mucositis.

\section{Subgroup analysis}

Subgroup analysis was performed by age $(\leq 45,>45$ years), sex (male, female), T category (T1, T2, T3), N category (N0, N1), and AJCC stage (stage II, III [T3NOM0]). No significant differences were found between the different strata in each subgroup (Table 5).

\section{Discussion}

This study directs to set side by side the efficacy and safety of IMRT plus chemotherapy versus IMRT alone in intermediate-risk NPC patients. We found approximate survival outcomes (5-year OS, DFS, LRFFS and DMFS) with IMRT alone and IMRT plus chemotherapy. Treatment-related toxicities were significantly more in the group treated with IMRT plus chemotherapy.

Nowadays, satisfactory disease control is relatively easily achieved with multimodality treatment in a variety of malignancies; however, the focus is to individualize treatment to achieve the best possible results in each patient. There are still some differing opinions on whether the benefit gained with radiotherapy in stage II and T3N0M0 NPC could be enhanced by the addition of chemotherapy. Guo et al. reported that the addition of chemotherapy could improve LRRFS (HR $=0.263$, 95\% CI: $0.083-0.839 ; P=0.024$ ), especially for T1N1 patients (HR $=0.209$, 95\% CI: 0.046-0.954; $P=0.043$ ) [11]. However, our pair-matched analysis of 124 stage II and T3NOMO NPC patients showed no significant survival benefit with the use of IMRT plus chemotherapy. Our results are in line with a retrospective study by Xu et al. that demonstrated similar OS, LRRFS, and DMFS in stage II NPC patients treated with IMRT alone and with IMRT plus chemotherapy. Patients with T3N0M0 NPC represent a group at special risk for distant metastasis, but our study found almost similar 5-year OS in patients treated with IMRT plus chemotherapy and with IMRT alone. Multivariate analyses showed that treatment regimen (IMRT/chemotherapy vs. IMRT-alone) was not an independent prognostic factor for OS in these patients. A meta-analysis by Cheng et al. also found similar OS, LRRFS, and DMFS in stage III (T3NOMO) NPC patients treated with CCRT and with IMRT alone [12]. In subgroup analysis, The IMRT plus chemotherapy showed longer DFS compared to the IMRT alone in stage III (T3N0M0) NPC patients, The possible reasons may be due to the small number of patients in T3NOMO subgroup. The benefits of adding chemotherapy to T3N0M0 needs to be confirmed by prospective studies.

Table 5 Analysis of survival outcomes in different subgroups of the IMRT group versus the IMRT/chemo-therapy group

\begin{tabular}{|c|c|c|c|c|c|c|c|c|}
\hline Factor & OS & $P$ & DFS & $P$ & LRRFS & $P$ & DMFS & $P$ \\
\hline \multicolumn{9}{|l|}{ Age } \\
\hline$\leq 45$ years & $86.7 \%$ vs. $96.0 \%$ & 0.282 & $80.0 \%$ vs. $92.0 \%$ & 0.238 & $93.3 \%$ vs. $96.0 \%$ & 0.696 & $86.7 \%$ vs. $96.0 \%$ & 0.299 \\
\hline$>45$ years & $93.6 \%$ vs. $86.5 \%$ & 0.257 & $89.4 \%$ vs. $86.5 \%$ & 0.620 & $97.9 \%$ vs. $94.6 \%$ & 0.415 & $93.6 \%$ vs. $94.6 \%$ & 0.369 \\
\hline \multicolumn{9}{|l|}{ Sex } \\
\hline Male & $90.9 \%$ vs. $90.9 \%$ & 0.980 & $84.1 \%$ vs. $88.6 \%$ & 0.581 & $95.5 \%$ vs. $93.2 \%$ & 0.643 & $90.9 \%$ vs. $95.5 \%$ & 0.708 \\
\hline Female & $94.4 \%$ vs. $88.9 \%$ & 0.553 & $94.4 \%$ vs. $88.9 \%$ & 0.553 & $100 \%$ vs .100\% & 1.000 & $94.4 \%$ vs. $94.4 \%$ & 0.504 \\
\hline \multicolumn{9}{|l|}{ T category } \\
\hline $\mathrm{T} 1$ & $100 \%$ vs. $94.4 \%$ & 0.378 & $100 \%$ vs. $94.4 \%$ & 0.378 & $100 \%$ vs. $94.4 \%$ & 0.378 & $100 \%$ vs. $100 \%$ & 1.000 \\
\hline $\mathrm{T} 2$ & $92.7 \%$ vs. $94.1 \%$ & 0.825 & $87.8 \%$ vs. $91.2 \%$ & 0.639 & $97.6 \%$ vs. $94.1 \%$ & 0.452 & $90.2 \%$ vs. $94.1 \%$ & 0.571 \\
\hline T3 & $71.4 \%$ vs $70.0 \%$ & 0.907 & $51.1 \%$ vs. $70.0 \%$ & 0.791 & $100 \%$ vs. $100 \%$ & 1.000 & $71.4 \%$ vs. $90.0 \%$ & 0.362 \\
\hline \multicolumn{9}{|l|}{$\mathrm{N}$ category } \\
\hline No & $90.5 \%$ vs. $84.2 \%$ & 0.539 & $85.7 \%$ vs. $84.2 \%$ & 0.817 & $95.2 \%$ vs. $100 \%$ & 0.342 & $95.2 \%$ vs. $94.7 \%$ & 0.215 \\
\hline N1 & $92.7 \%$ vs. $93.0 \%$ & 0.964 & $87.8 \%$ vs. $90.7 \%$ & 0.678 & $97.6 \%$ vs. $93.0 \%$ & 0.331 & $90.2 \%$ vs. $95.3 \%$ & 0.389 \\
\hline \multicolumn{9}{|l|}{ TNM stage } \\
\hline$\|$ & $94.5 \%$ vs. $94.2 \%$ & 0.935 & $90.9 \%$ vs.92.3\% & 0.802 & $98.2 \%$ vs. $94.2 \%$ & 0.283 & $92.7 \%$ vs. $96.2 \%$ & 0.462 \\
\hline III (T3NOMO) & $71.4 \%$ vs. $70.0 \%$ & 0.907 & $57.1 \%$ vs.70.0\% & 0.801 & $85.7 \%$ vs.100\% & 0.232 & $85.7 \%$ vs. $90.0 \%$ & 0.648 \\
\hline
\end{tabular}

OS Overall survival, DFS Disease-free survival, LRRFS Locoregional relapse-free survival, DMFS Distant metastasis-free survival 
In the present study, the overall incidence of grade 3 acute toxic effects was higher in the IMRT/chemotherapy group than in the IMRT-only group; significantly higher incidence was seen of grade 3 leukopenia/neutropenia, nausea/vomiting, and mucositis. Some earlier studies have reported similar findings [7, 13]. We separated the patients into different subgroups according to various baseline factors. No significant difference was seen between the different strata in each subgroup. Therefore, assessment of patients with precise population stratification may reduce the benefits of CCRT to a non-significant effect, which could apply equally to other diseases.

We offer two possible explanations for the similarity in survival outcomes between the IMRT/chemotherapy and the IMRT-alone groups in this study. First, IMRT provides better local tumor control than 2D-RT [14, 15] and so the potential gains achieved with the addition of chemotherapy may not as obvious [16]. Second, the high frequency of severe adverse reactions in patients treated with IMRT/chemotherapy may have masked any survival benefit in this group [17]. Lan et al. have also found that addition of chemotherapy to IMRT does not significantly improve OS; additionally, the authors reported that the higher the incidence of grade 3-4 acute toxicities (especially hematological events such as leucopenia and neutropenia [13]) increases the possibility of discontinuation of treatment. Thus, it seems that IMRT alone may be more suitable than CCRT for patients with stage II and T3NOM0 NPC.

Some limitations of this study should be kept in mind when interpreting the results. First, this is a retrospective study, and some bias is inevitable; for example, patients received different chemotherapy regimens, and this may have influenced the results. Second, the sample size was relatively small.

\section{Conclusion}

In intermediate-risk (stage II and $\mathrm{T}_{3} \mathrm{~N}_{0} \mathrm{M}_{0}$ ) NPC, IMRT provides survival outcome comparable to that with IMRT plus chemotherapy. Moreover, grade 3 acute toxicities are fewer with IMRT alone than with IMRT plus chemotherapy. Well-designed large randomized clinical trials comparing CCRT with IMRT alone are needed to confirm our findings and to help formulate individualized therapies for stage II and T3NOM0 NPC patients.

\footnotetext{
Abbreviations

2D-RT: Two-dimensional radiotherapy; 3DCRT: Three-dimensional conformal radiotherapy; CCRT: Concurrent chemoradiotherapy; CECT: Contrastenhanced computed tomography; Cl: Confidence interval; CTV: Clinical target volume; DFS: Distant failure-free survival; DMFS: Distant metastasis-free survival; GTVnd: Metastatic cervical lymph nodes; GTVnx: Gross tumor volume; HR: Hazard ratio; IMRT: Intensity-modulated radiotherapy; LRRFS: Locoregional relapse-free survival; MRI: Magnetic resonance imaging; NPC: Nasopharyngeal carcinoma; OS: Overall survival; PTV: Planning target volume; RTOG: Radiation Therapy Oncology Group; UICC/AJCC: International
}

Union against Cancer/American Joint Committee on Cancer; WHO: World Health Organization

\section{Acknowledgements \\ Not applicable.}

\section{Authors' contributions}

OA: Developed the concept, contributed to statistical analysis, did chart reviews and wrote maximum sections of the paper. SL: Contributed to statistical analysis and reviewed sections of the paper. RZ: Did chart reviews and wrote section of the paper. NT: Contributed in managing patients. ML: Helped in collection and organizing the data. BZ: Reviewed chart and section of paper. SS: Contributed to the statistical analysis. RR: Contributed patients, did chart reviews. JA: Contributed in managing and calculating the results. WJ: Managed patients and collected data for the paper. All authors read and approved the final manuscript.

\section{Funding}

This work was supported by the National Natural Science Foundation of China (Nos. 81560443, 81760546) and the Scientific Research and Technology Development Program of Guilin (Nos. 20170109-22, 20170109-46), the Natural Science Foundation of Guangxi (No. 2018GXNSFAA138100), the Natural Science Foundation Key Projects of Guangxi (2018GXNSFDA050021), the Key Research and Development Program of Guangxi (AB19110016), and the Scientific Research Program of the Health Commission of Guangxi Zhuang Autonomous Region (Z2016820).

\section{Availability of data and materials}

All data generated or analysed during this study are included in this published article.

\section{Ethics approval and consent to participate}

This study was approved by the Medical Ethics Committee of Affiliated Hospital of Guilin Medical University, Nanxishan Hospital of Guangxi Zhuang Autonomous Region and Wuzhou Red Cross Hospital. All patients provided informed consent

\section{Consent for publication}

Not applicable.

\section{Competing interests}

The authors declare that they have no competing interests.

\section{Author details}

${ }^{1}$ Department of Radiation Oncology, Affiliated Hospital of Guilin Medical University, 15 Lequn Road, Guilin 541001, People's Republic of China. ${ }^{2}$ College of International Education of Guilin Medical University, Guilin 541001, PR China. ${ }^{3}$ Department of Medicine, Nanxishan Hospital of Guangxi Zhuang Autonomous Region, Guilin 541004, China. ${ }^{4}$ Department of Medical Oncology, Affiliated Hospital of Guilin Medical University, Guilin 541001, China. ${ }^{5}$ Department of Radiation Oncology, Wuzhou Red Cross Hospital, Wuzhou 543002, China. ${ }^{6}$ Department of Oncology, People's Hospital of Gongcheng Yao Autonomous County, Guilin 542500, China.

Received: 5 November 2019 Accepted: 2 March 2020

Published online: 16 March 2020

\section{References}

1. Wi W, Sham JS. Nasopharyngeal carcinoma. Lancet. 2005;365(9476):2041-54.

2. Lee AW, Ma BB, Ng WT, Chan AT. Management of nasopharyngeal carcinoma: current practice and future perspective. J Clin Oncol. 2015; 33(29):3356-64.

3. Chan AT, Leung SF, Ngan RK, et al. Overall survival after concurrent cisplatin-radiotherapy compared with radiotherapy alone in locoregionally advanced nasopharyngeal carcinoma. J Natl Cancer Inst. 2005;97(7):536-9.

4. Chen QY, Wen YF, Guo L, et al. Concurrent chemoradiotherapy vs radiotherapy alone in stage II nasopharyngeal carcinoma: phase II randomized trial. J Natl Cancer Inst. 2011;103(23):1761-70.

5. Chen L, Mao YP, Xie FY, et al. The seventh edition of the UICC/AJCC staging system for nasopharyngeal carcinoma is prognostically useful for patients treated with intensity-modulated radiotherapy from an endemic area in China. Radiother Oncol. 2012;104(3):331-7. 
6. You R, Cao YS, Huang PY, et al. The changing therapeutic role of chemoradiotherapy for loco-regionally advanced nasopharyngeal carcinoma from two/three-dimensional radiotherapy to intensity-modulated radiotherapy: a network meta-analysis. Theranostics. 2017:7(19):4825-35.

7. Xu T, Zhou X, Shen C, Hu C. Suggestions for surveillance and radiation strategy in nasopharyngeal carcinoma treated with IMRT: based on hazardrate and patterns of recurrence. Oral Oncol. 2018;76(undefined):61-7.

8. Sun $Y$, Tang $L L$, Chen $L$, et al. Promising treatment outcomes of intensitymodulated radiation therapy for nasopharyngeal carcinoma patients with NO disease according to the seventh edition of the AJCC staging system. BMC Cancer. 2012;12:68.

9. Zhang MX, Li J, Shen GP, et al. Intensity-modulated radiotherapy prolongs the survival of patients with nasopharyngeal carcinoma compared with conventional two-dimensional radiotherapy: a 10-year experience with a large cohort and long follow-up. Eur J Cancer. 2015:51(17):2587-95.

10. Edge SB, Compton CC. The American Joint Committee on Cancer: the 7th edition of the AJCC cancer staging manual and the future of TNM. Ann Surg Oncol. 2010;17(6):1471-4.

11. Guo Q, Lu T, Lin S, et al. Long-term survival of nasopharyngeal carcinoma patients with stage II in intensity-modulated radiation therapy era. Jpn J Clin Oncol. 2016;46(3):241-7.

12. Xu C, Zhang LH, Chen YP, et al. Chemoradiotherapy versus radiotherapy alone in stage II nasopharyngeal carcinoma: a systemic review and metaanalysis of 2138 patients. J Cancer. 2017;8(2):287-97.

13. Lan XW, Xiao Y, Zou XB, et al. Outcomes of adding induction chemotherapy to concurrent chemoradiotherapy for stage T3N0-1 nasopharyngeal carcinoma: a propensity-matched study. Onco Targets Ther. 2017; 10(undefined):3853-60.

14. Lai SZ, Li WF, Chen L, et al. How does intensity-modulated radiotherapy versus conventional two-dimensional radiotherapy influence the treatment results in nasopharyngeal carcinoma patients? Int J Radiat Oncol Biol Phys. 2011;80(3):661-8.

15. Wolden SL, Chen WC, Pfister DG, et al. Intensity-modulated radiation therapy (IMRT) for nasopharynx cancer: update of the Memorial SloanKettering experience. Int J Radiat Oncol Biol Phys. 2006;64(1):57-62.

16. Carman J, Strojan P. Nasopharyngeal carcinoma in Slovenia, 1990-2003 (results of treatment with conventional two-dimensional radiotherapy). Rep Pract Oncol Radiother. 2012;17(2):71-8.

17. Ouyang PY, Zhang LN, Lan XW, et al. The significant survival advantage of female sex in nasopharyngeal carcinoma: a propensity-matched analysis. $\mathrm{Br}$ J Cancer. 2015;112(9):1554-61.

\section{Publisher's Note}

Springer Nature remains neutral with regard to jurisdictional claims in published maps and institutional affiliations.

Ready to submit your research? Choose BMC and benefit from:

- fast, convenient online submission

- thorough peer review by experienced researchers in your field

- rapid publication on acceptance

- support for research data, including large and complex data types

- gold Open Access which fosters wider collaboration and increased citations

- maximum visibility for your research: over $100 \mathrm{M}$ website views per year

At $\mathrm{BMC}$, research is always in progress.

Learn more biomedcentral.com/submissions 